\title{
A Universidade e a Eletrônica
}

\author{
The University and the Electronics
}

O homem deve o ter sobrevivido até agora, neste planeta, ao desenvolvimento da capacidade de aprender e de transmitir o que aprendeu e assim poder construir o próprio ambiente para viver. $E$ isso porque, como partícipe da biosfera e à semelhança dos demais seres vivos, necessita de se reproduzir herdando o patrimônio gênico, de crescer, de absorver energia, de ter resposta sensível aos estímulos externos e de se adaptar ao ambiente. Esta última necessidade faz-se, seja sob a forma de desenvolvimento de orgãos e estruturas, seja sob a forma de traços comportamentais ou, melhor dizendo, por ambas. Quanto a sensibilidade ao meio, há que ser encarada sob dois aspectos, quais sejam, o de explorar o ambiente e o da capacidade de solucionar problemas inerentes à própria existência (Popper', 1984). Para tanto, a evolução da linguagem adquiriu significado essencial na esnécie humana, uma vez que há que ser considerada como produto de sua própria mente.

Desde há cerca de 10.000 anos a populaçăo, organizada em sociedade, atribuiu a alguns de seus componentes a incumbência específica de produzir e de preservar o acervo de conhecimentos e os meios de difundi-los. De início, foram os sacerdotes e, como nåo podia deixar de ser, a propagação limitava-se à via verbal. Porém, como a memória é sempre acompanhada de falhas e é propícia aos desvios da imaginaçāo, surgiu a necessidade de fixá-la mediante a escrita e, assim, manter idelevelmente as informações ("verba volant scriptu manent"). Em decorrência, originou-se a necessidade de profissionais a quem se pudesse atribuir a funçâo de reproduzi-las graficamente. Eram os chamados "escribas", precursores dos escreventes cartoriais de agora. Nessa mesma ordem de analogias, poder-se-ia considera-los também como precursores dos atuais digitadores da informática.

Assim pois, em diferentes lugares do mundo surgiram instituiçôes precipuamente destinadas à procura e à divulgação do conhecimento. Deixando o âmbito sacerdotal estrito, os assim chamados "homens eruditos" ali se congregavam para o exercício dessas atividades. Tais foram os modelos iniciais de Nínive, Assíria e de Alexandria, Egito, na antiguidade, das universidades medievais até as que, a partir do século passado, ou da época do iluminismo, perduraram até hoje. Neles, os alunos iam em busca da informação, transmitida pelos que a possuiam, isto $\epsilon$, os intelectuais ("intellectus" = conhecimento). De maneira notável, esse sistema manteve a sua estabilidade por cerca de 2.500 anos, ou seja, até a época atual.

Não obstante, assiste-se na atualidade à ocorrência de nítidos sintomas de desarranjo desse modelo. Ao que tudo indica, a produção intelectual chegou a tal nível que esse sistema não mais consegue dar vazão satisfatória ao volume de informações daí resultante, e que crescem continuamente em número. Diante dessa situação, o processo tradicional de transmissåo vem sendo paulatinamente comprometido pelo avanço da tecnologia que permite maior velocidade e eficácia. Em decorrência, o modelo universitário tido até agora como o melhor, passa a enfrentar sérias ameaças à sua estabilidade. E esta, considerada no tríplice aspecto de campos de conhecimento, de acervo e de transmissão da informação, ou seja, do ensino.

Na medida em que cresce o vulto de informaçōes, as especialidades tornam-se cada vez mais restritas. Isso significa que cada vez maiores dificuldades surgem para que a pesquisa e o ensino no âmbito universitário possam cobrir amplos campos de conhecimento. Para tanto, nas sociedades do primeiro mundo, estima-se que haveria de dobrar a disponibilidade de recursos humanos a cada 5-10 anos (Noam², 1995). Obviamente não se trata de algo que seja exequivel, nem sob o ponto de vista econômico e nem 
organizacional. Consequientemente, a universidade deixa de cobrir grandes extensōes do saber e, na melhor das hipóteses, passa a se tornar cada vez mais especializada. Com isso formam-se grupos que se dedicam a estudos progressivamente específicos, com evidente isolamento profissional, em prejuízo de interações dentro da própria universidade. Em contrapartida, o grau de desenvolvimento da tecnologia de comunicação propicia que colegas da especialidade sejam encontrados mais freqüentemente fora do âmbito de trabalho. Diante disso, aquelas interaçōes passam a ser feitas predominantemente entre especialistas fisicamente distantes entre si. Trata-se da famosa "internacionalizaçāo" do conhecimento, paradigma atual na avaliação da atividade produtiva. Daí a razāo de valorizar, a mais das vezes de maneira excessiva, a formação "exógena" em detrimento da "endógena". Curiosamente, apesar disso persiste a prática de realizar e promover congressos e simpósios. Verdade seja dita, tais reuniōes adquirem, cada vez mais, conotações turísticas e, cada vez menos, científicas propriamente ditas.

A segunda feição universitária vem a ser aquela que diz respeito à preservação do acervo de informaçōes. Pode-se ter idéia da importância dessa função ao se atentar que o nível da universidade tem sido julgado pelo đe sua biblioteca. Todavia, a evolução econômica e tecnológica também conspiram para que ocorram mudanças nesse setor. A contínua elevação do custo de assinaturas e aquisição de publicaçóes, motivada pelo incremento considerável da produção de informaçőes, tem levado a situaçōes de dificuldade para o enriquecimento e manutenção do acervo. Em vista disso, a atenção dirige-se para alternativas, dentre as quais a eletrônica desempenha papel predominante. Esta, tendo em vista sua maior eficácia no armazenamento, no acesso e na recuperação da informação. Por esse motivo, as bibliotecas têmse gradualmente voltado para investimentos na área de informática. Em continuando essa tendência, terse-á chegado à obsolescência do acervo tradicional, uma vez que a computação permitirá o preenchimento de seu papel, de maneira tanto ou mesmo melhor. Contudo, com isso terá desaparecido ou, ao menos, será substancialmente alterado, esse aspecto da universidade.

A terceira função universitária é representada pelo ensino, ou seja, a referida transmissão das informações. Isso é atualmente feito mediante a interaçāo professor-aluno, a exemplo do que vem acontecendo há cerca de dois milênios e mejo. Nāo obstante o longo caminho percorrido, esse processo encontrase prestes a ser substancialmente modificado. Uma das razōes vem a ser a já mencionada tendência à especializaçăo, por um lado levando à escassez de mestres que dominem áreas mais amplas do conhecimento e, por outro, à diminuiçāo do interesse por tudo que nāo seja imediatamente aplicável e, principalmente, rentável. Por sua vez, o desenvolvimento da área de eietrônica vem resultando em alternativas tecnológicas de ensino, cada vez mais desviando-o do modelo tradicional. Essas técnicas transformaramse em ferramentas de eficácia promissora. Tais sāo, as aulas disponíveis em vídeo, o acesso eletrônico a exercícios e a textos de leitura, a interação, por essa via, com múltiplos professores e instituiçōes, além de programas, traduçōes, experiências didáticas e grande variedade de facilidades audio-visuais. $\mathrm{O}$ atrativo principal desses novos sistemas não reside tanto na maior eficácia, mas sim no seu menor custo em relaçāo ao de modelo professor-aluno. Por meio deles, torna-se possível propagar o ensino a milhares ou mesmo dezenas de milhares de pessoas pelo mundo. Para isso, pode-se lançar māo da tecnologia de transmissāo via satélite, rádio e televisāo. Isso torna-se particularmente atrativo para todos aqueles que desejam realizar cursos, mas não o podem fazer por nāo disporem de tempo suficiente, que é exigido pelo processo de ensino tradicional.

Diante desse quadro, compreende-se que o ensino universitário se encontre ameaçado por alteraçôes substanciais. Acresce considerar que a divulgaçāo eletrônica tende a sair do âmbito universitário, migrando para o de empresas comerciais. Em nosso meio, pode-se observar com freqüência a oferta de programas em vídeo para o aprendizado de idiomas. O passo seguinte será o da oferta de cursos profissionais completos fazendo jus a certificados de conclusão e mesmo de diplomas.

Diante de tais situaçōes, caberá perguntar como a universidade poderá sobreviver a tais impactos. A questão vem a ser, fundamentalmente, se $o$ atual sistema tradicional poderá sustentar-se economicamente face ao fluxo de informações proveniente da comunicação eletrônica. Claro está que não se trata de questionar a importância e o significado da pesquisa e do ensino, mas sim do modelo no qual eles são levados a efeito. Pergunta-se como a universidade poderá adaptar-se a tal tendência, ou seja, de substituição 
do modelo histórico da procura da informação pelo interessado, pelo da procura deste por parte daquela. De qualquer maneira, há de se atentar para certos pontos que, por fundamentais, é de se admitir que persistam. São eles:

1 - Em que pese o advento de alteraçōes, de maior ou menor profundidade, o ensino total é bem mais do que a simples transmissão de informaçōes.

2 - Trata-se de processo educativo que visa a concepção mental do conhecimento e pois, não pode prescindir de várias circunstâncias, dentre as quais destaca-se a atividade em grupo.

3 - A execução satisfatória das etapas fundamentais do processo educativo implica a proximidade física.

4 - Na pesquisa, a sediação física permite o emergir de grupos de excelência os quais, em que pese o fato de se comunicarem extensivamente com outros, distantes, servirão de pólos de atração para a juventude $e$ as gerações futuras.

5 - Com o quadro atual de intensa produção de conhecimentos, é do interesse da sociedade que continue no âmbito universitário o desempenho do papel de guarda da cultura adquirida.

6 - A realização da pesquisa básica, sem interesse comercial imediato, continua sendo fundamental para a sobrevivência da humanidade culta e não há como deixar de atribuí-la à universidade.

Frente a tais considerações, não se pode negar o papel da universidade na defesa da cultura contra as ameaças da civilização. Estas sâo representadas essencialmente pelo mau uso das conquistas tecnológicas que acabam por comprometer a qualidade de vida humana. Não se trata aqui de discorrer sobre o ideal utópico pelo qual a técnica libertaria o homem, permitindo-lhe viver em liberdade total. E até porque nunca, na história da humanidade, houve tamanha quantidade, verdadeira parafernália, de implementos de toda sorte e, ao mesmo tempo, nunca o homem tem sofrido tanto do chamado "mal-estar na cultura" (Kunert', 1995), O que se pretende, por conclusão, é ponderar sobre o fato inconteste que cabe à universidade colocar, na justa medida ética, uma civilização eivada de tecnicismo. Este, ao invés da liberdade, oferece ao ser humano a servidão às necessidades adquiridas. E aquele será, como sempre o foi, o papel central da universidade.

\section{Oswaldo Paulo Forattini \\ Editor Científico}

\section{Referências Bibliográficas}

1. KLNERT, G. A aboliçào da cultura pela civilizaçào. Humboldt, n.70:4-5, 1995.

2. NOAM, E. M. Electronics and the dim future of the university. Science, 270:247-9. 1995.

3. POPPER, K. R. Evolutionary epistemology, In: Pollard, J.W. (Ed.) - Et'olutionan' theon: patbs into the future. Chichester. John Wiley \& Sons, 1984. p. 239-55. 